\title{
ÉTICAS SITUADAS: EXPERTOS, CONTROVERSIAS Y PARTICIPACIÓN CIUDADANA
}

\author{
Situated Ethics: Experts, Controversies and Citizen \\ Participation
}

\section{Ética situada: especialistas, controvérsias e participação cidadã}

\author{
María Jesús BuXó ReY \\ Universidad de Barcelona \\ mjbuxo@telefonica.net
}

Fecha de recepción10/03/2021

Fecha de aceptación: 15/03/2021

RESUMEN: Ética y Antropología constituyen el reto que Carmelo Lisón pone a la imaginación antropológica ante la complejidad de los problemas culturales y sociales afectados por la creciente globalización tecno-biológica. La denominada pandemia por la Covid-19 es parte de ese reto por cuanto el escenario donde se dirimen los riesgos representa acciones inciertas y poco resolutivas mientras los actores, la gobernanza política y las corporaciones financieras, farmacéuticas y mediáticas, se apropian del discurso, las narrativas y las decisiones en exclusión del dialogo y el debate de acceso abierto entre las instituciones científicas y la participación ciudadana.

Palabras clave: Antropoética; transciencia; debate público; deliberación riesgos.

ABSTRACT: Ethics and Anthropology, according to Carmelo Lisón, challenges the anthropological imagination when facing the complexity of cultural and social problems following the never-ending biotechnologized globalization process. Pandemics by Covid-19 is part of this challenge since the scene where risk solutions 
are played, shows resolutive deficiency by uncertain actions whereas actors political governance and finance corporations, pharmaceuticals and media- get hold of discourse, narratives and decisions while excluding the open access dialogue and debate between scientific institutions and citizen participation.

Keyowords: Anthropological ethics; trans-science; public debate; risk deliberation.

RESUMO: Ética e Antropologia constituem o desafio que Carmelo Lisón coloca a imaginação antropológica diante da complexidade dos problemas culturais e sociais afetados pela crescente globalização tecno-biológica. A denominada pandemia de Covid-19 é parte deste desafio por conta do cenário onde se dirimem os riscos, representa ações incertas e pouco resolutivas enquanto os atores, a governança política e as corporações financeiras, farmacêuticas e mediáticas, se apropriam do discurso, as narrativas e as decisões em exclusão do diálogo e o debate de acesso aberto entre as instituições cientificas e a participação cidadã.

Palavras-chave: ética antropológica; trans-ciência; debate público; deliberação de risco.

"Nada bay realmente puro" Carmelo Lisón Tolosana

\section{INTRODUCCIÓN}

Ética y Antropología es el título con el que Carmelo Lisón inaugura el encuentro sobre Antropología Aplicada en Iberoamérica. Desde la fascinación expresa el interés por las narraciones plurales que se crean ante cualquier problema cultural y social y el reto que esta pluralidad supone para la imaginación antropológica. Ante realidades cada vez más complejas, esta imaginación ha de ser capaz de abrirse a preguntas similares y metáforas análogas sobre la enfermedad, la muerte, el cuerpo y la identidad, aunque ahora situadas en la tecnologización creciente de la sociedad. Afirma así que enfocar esta realidad requiere ampliar las metodologías, así como refinar las conceptualizaciones y la creación de modelos, siendo el locus clave la antropoética. En sus palabras (2008: 17):

la maquinaria de la manipulación y del control esta siempre al acecho y la ideología se persona solapada; nada hay realmente puro.

¡Cuánto bien nos haría en la actual pandemia sus reflexiones! La antropología sin fronteras de sus seminarios, siempre abiertos a las voces en plural y la discusión, serían una guía ante la complejidad y la aceleración de los acontecimientos transculturales y su incidencia en los sistemas simbólicos por donde trasiegan en clave tecnológica la recreación de significados, metáforas y rituales, así como los 
valores y actitudes. Ciertamente, las Nuevas Tecnologías, tanto en su versión IA como en sus aplicaciones biomédicas, constituyen extensiones que impactan en la consideración y el tratamiento del cuerpo, la enfermedad y la identidad en su dimensión más íntima y génica hasta el punto de redefinir a los individuos como sujetos y objetos biotecnológicos simultáneamente (Buxó, 2010).

En términos culturales, el cocktail globalista IA y bionanotecnológico se acompaña de agendas y declaraciones cuyas narrativas high tech buscan idealizar una neo-realidad que irrumpe sin consideración en la diversidad cultural para uniformizarla transculturalmente. Los relatos dominantes se vehiculan a través de la portabilidad de la información mediática y propagandística, difundida en las redes y activada en una suerte de didáctica cuyo fin es conformar los estilos de vida en la transitividad abierta de las expresiones transgénero, transfamiliares, transhumanistas e, incluso, en la transciencia requerida para la ingeniería social en ámbitos tan controvertidos como los relativos a la salud pública, la muerte digna y la protección ambiental.

En su conjunto, los futuribles culturales que proyectan las agendas y las ingenierías sociales del poder político y las corporaciones biotech y financieras, hacen del transculturalismo una apuesta que se revela opaca e incierta al afectar la protección de la diversidad cultural, restringir la autonomía personal, la capacidad de decisión y, finalmente, la libertad de expresión.

Sin duda, el globalismo acelerado precipita cambios incontrolables en las configuraciones culturales locales y, consecuentemente, en las fórmulas para resolver sus problemas específicos. Esto requiere plantearse, como antaño, aspectos éticos relativos a los derechos humanos, siempre atentos a la cultura cívica cuyas exigencias básicas son autonomía, consentimiento y participación. En las condiciones de la pandemia por Covid-19 a gran escala, las políticas glocales de evitación y control de contagios y enfermedades comparten restricciones sociales a la vieja usanza, confinamientos, mascarillas, distancias interpersonales y perimetrales, prohibiciones y sanciones por carecer de vías biomédicas alternativas. A excepción de la vacuna que pasa a ser la gran expectativa precisamente por diferir de la de antaño, un innovador fármaco génico autorizado como solución de emergencia.

De interés antropoético es la desconsideración de las políticas y organizaciones sanitarias por los derechos de la sociedad civil de la cual solo se espera aceptación y sometimiento. Las carencias más evidentes se manifiestan en la comunicación institucional que, mediada por un experto, marca las restricciones aportando información estadística aproximada con lo cual conmina a todos los sectores económicos, profesionales y ciudadanía en general a compartir la unanimidad de criterios y la uniformidad de conductas. Y, cuanto más confusa es la definición de necesidades y la ineficacia de las medidas y servicios, mayor es la exigencia de supeditarse, voluntariamente o mediante sanciones, al orden superior del Estado.

Todo encubrimiento u opacidad en las políticas de comunicación sanitaria no tiene otro fin que confundir, intimidar y expropiar las decisiones sobre la salud. De ahí la preocupación ética por la autonomía personal, la libertad de expresión, 
y, como bien expresa Illich (1973), por cuidar que el experto intimidante no robe el poder del individuo para luchar por sí mismo. Así, en asociación al riesgo sanitario y ambiental, se suma el riesgo moral de redistribuir soluciones injustas por no atender a necesidades y decisiones en su contexto. Y esto no solo afecta los derechos, sino que fuerza la idea de obligación moral univoca lo cual socava la confianza cívica hecha de relaciones morales múltiples y flexibles acordes a los problemas y las situaciones.

\section{II. ÉTICAS SITUADAS Y EN ACCIÓN}

Desde la Declaración Universal de los Derechos Humanos hasta los múltiples informes de la Unesco (1995) sobre la Creatividad Cultural, siempre se ha difundido el mensaje que la diversidad cultural es fuente de intercambios, innovación y creatividad. Esta diversidad es necesaria para la especie humana por ser patrimonio común, parte fundamental de la identidad de la persona, además de fomentar la igualdad más allá de lo común y lo diferente.

En los años 40 del siglo XX, la Antropología Cultural centraba sus cuitas en los derechos de las comunidades indígenas que habían estado supeditadas por la colonización y la imposición de los sistemas éticos occidentales. Fuesen religiosos o jurídicos, éstos no habían hecho otra cosa que humillar voluntades, vulnerar derechos e imponer principios para legitimar la conquista de las tierras y apropiarse de los recursos. De esta sensibilidad nació en 1947 un Statement for Human Rights, que fue adoptado por la American Anthropological Association (AAA), en el cual se manifestaba la repulsa contra el racismo y el nazismo y a la vez el requerimiento de apoyar la libertad y la dignidad de las comunidades indígenas y sus derechos lingüísticos. Su impulsor, Melville Herskovits, especialista en el estudio comparativo de las culturas, fue consultor de la Unesco en la elaboración del documento de la Declaración de los DDHH publicada un año después, en 1948.

Entre la Antropología Cultural y la primera Declaración Universal hay discrepancias relativas a la prioridad y la relación entre los valores particulares y los universales por cuanto éstos priman los juicios normativos que pueden restringir, limitar o ir contra prácticas culturales particulares. En su libro sobre el Relativismo Cultural, Herskovits (1973) señala que distinguir y reconocer derechos y valores requiere una atención descriptiva, antes de pasar a una solución prescriptiva como la que representa la Declaración universal de los DH. En realidad, sus disposiciones y principios no son testimonios descriptivos de un conjunto de hechos morales universales, sino más bien una declaración de intenciones realizada por parte de la comunidad internacional para modelar las sociedades en la línea de ciertos estándares preferidos. Y, las consecuencias de esta remodelación pueden generar incompatibilidades por el hecho de imponer o negar sin matices las ideas de los Otros, afectar su privacidad, generar frustración, en aspectos relativos a las relaciones entre el individuo y el colectivo y al mismo valor de la vida. 
Debate común, desde la emancipación ilustrada de la Declaración de los derechos del hombre y del ciudadano (1789) que sigue aportando matices y oponiendo posiciones. En traducción moderna, el comunitarismo versus el individualismo de los principios. El individuo es parte de un conjunto cuya fuerza moral reside en la particularidad de ser miembro de un estado, nación y comunidad (Sandel, 1982) versus una concepción de la moralidad como facultad surgida de la razón, de lo cual cabe extraer una regla universal expresable en leyes y obligaciones fijas (Rawls, 2006). Sea uno u otro el referente ideativo, las consecuencias que impiden el progreso moral, casi siempre son relativas a desconsiderar al Otro y sus problemas.

Ya en el territorio de la salud pública, la Declaración Universal sobre Bioética y Derechos Humanos (2005) emerge especialmente a raíz de controversias sobre las aplicaciones de la biotecnología y la biomedicina, la intensificación vía ingeniería genética y nanotecnológica que augura implantes, o conexión de dispositivos, y la inoculación de tratamientos para perfeccionar el cuerpo, sea para mejorar el estado de salud, remediar enfermedades y disminuciones físicas y/o potenciar la cognición inteligente, sin olvidar la publicidad oportunista de modelos biónicos probables con los que gusta futurizar la propaganda transhumanista.

En este sentido, se recomiendan actos y acciones que los gobiernos y las instituciones sanitarias no pueden hacer a sus ciudadanos: la exclusión de la atención sanitaria, supeditarles a la medicalización o el encarnizamiento terapéutico, no aplicar el principio de precaución a los avances y experimentos biotecnológicos y controlar los intereses de las industrias farmacéuticas. Aunque siempre priva la formalidad de los principios (artículo 12):

Se debería tener debidamente en cuenta la importancia de la diversidad cultural y del pluralismo. No obstante, estas consideraciones no habrán de invocarse para atentar contra la dignidad humana, los derechos humanos y las libertades fundamentales o los principios enunciados en la presente Declaración, ni tampoco para limitar su alcance.

Ahora bien, esta afirmación no facilita, más bien dificulta conciliar valores en competición respecto a las finalidades de la vida, la justicia y la igualdad, de ahí la necesidad de activar éticas situadas. Sin negar el rigor de los DDHH en su capacidad para establecer acciones legales y políticas, es preciso atender a lo que especifica el preámbulo de la "Declaración sobre Antropología y Derechos Humanos", redactada por el Comité de Derechos Humanos de la American Anthropological Association (1999):

El conocimiento de la capacidad para la cultura en todas las sociedades tiene implicaciones éticas para la igualdad de oportunidades de todas las culturas, sociedades y personas, así como para llevar a término esta capacidad en sus identidades culturales y vidas sociales. Sin embargo, el ambiente global está lleno de violencia que se perpetra por parte de los estados, sus representantes y corporaciones, y otros actores. La violencia limita la humanidad de los individuos y las colectividades [...] 
y la AAA tiene la responsabilidad ética de protestar y oponerse a toda suerte de privación cultural. Esto implica poner en la base los derechos humanos y la legislación internacional, pero también expandir la Declaración de los DDHH para incluir áreas no necesariamente consideradas por la legislación internacional como los derechos individuales, culturales y sociales, así como un ambiente limpio y seguro.

La propuesta de la AAA incorpora los derechos humanos relativos a los principios internacionales, pero no se limita a los mismos puesto que la uniformidad legal puede traducirse en una aplicación burocrática abusiva. Es notorio que los DDHH han pasado a ser un discurso moral transnacional emergente. No hay Constitución, ni líder que se precie, que no los incorpore en sus estatutos y discursos, de ahí que una aplicación politizada en agendas y proyectos varios puedan inducir prácticas perversas o simplemente inadecuadas.

En este sentido, Rorty (1997) considera que los DDHH son los motores inmóviles de la mayoría de las políticas contemporáneas. Desde un punto de vista pragmático, la noción de derechos humanos inalienables no es mejor ni peor que el eslogan de la obediencia a la voluntad divina. Cuando se les invoca como motores inmóviles, esos eslóganes son sencillamente una manera de decir que no va más, que hemos agotado nuestros recursos argumentativos. Así, hablar de DDHH, como hablar de Dios, o el honor de la familia, o la dignidad de la persona, no es algo que resulte apropiado para la crítica y el análisis filosófico, ni tampoco para el progreso moral. Esto es, son anuncios de que se ha pensado el problema y se ha tomado una decisión, pero no son razones para la acción.

Y, en ese propósito converge con aquellos filósofos del derecho (Ignatieff, 2001) que advierten que los DDHH deben ser informados por los problemas evitando actuar como una religión secular. Otorgarle superioridad moral, y quedarse en la retórica, no solo anula o disminuye la fuerza ética de las recomendaciones y acciones, sino que pierde eficacia legal para imponerse a las agendas y recursos abusivos de los estados y las corporaciones multinacionales del totalitarismo global.

En esta línea, el particularismo no es antagónico a los DDHH y su aspiración universal. Intenta evitar que los DDHH queden reducidos a frases hechas sobre metas, aspiraciones, o simples apelaciones a la dignidad, cuya altisonancia tiende a la ambigüedad y se traduce en ineficacia moral. Macklin (2003) y Pinker (2008) se preguntan hasta qué punto es útil la palabra dignidad para el análisis ético de la actividad médica, y si no es una forma amable que debería dejar paso a lo que hay que hablar, esto es, el respeto a la autonomía de las personas y los pacientes.

Quedando claro que el relativismo cultural no quiere decir relativismo moral, las éticas situadas van más allá de referenciarse en un conjunto de principios, protocolos uniformes, apelaciones a la conciencia y deberes, para situarse en las prácticas con fines concretos. No se define en lo normativo, ni rebusca en las esencias de lo bueno y lo malo pues los problemas no remiten a un canon teórico acomodado entre conceptos políticamente correctos. De ahí la conveniencia de 
superar los conceptos cálidos: dignidad, flexibilidad, tolerancia que, por su cualidad multisemántica en positivo, instruyen un lenguaje ambiguo por exceso.

En definitiva, una ética situada enfoca la acción en los contextos sociales donde se definen los problemas y se busca darles solución o alternativas de solución. Como señala Blackburn (1998), la ética no se sigue, se vive, la ética se manifiesta en reacciones prácticas hacia las cosas, por las respuestas en situaciones concretas y en el grado de compromiso. Sistemas éticos que no por situados son estáticos, sino que están en evolución, a veces acelerada, por lo cual hay que profundizar en los mecanismos y las formas de servir deberes éticos hacia la población, los estilos de vida y libertad personal que puedan estar comprometidos, denostados o vulnerados por ser incluso calificados como resistencia, disidencia y emancipación.

La etnografía, intérprete de procesos sociales observados empíricamente, aporta información relativa a los sistemas de valores y actitudes cuya materia prima son percepciones, afectos, prejuicios, gustos, intereses y motivaciones que permiten observar estándares de conducta básicos situados contextualmente. Y, en la comparativa etnográfica, además se pone en evidencia que los sistemas morales y éticos varían en forma y contenido y, además, se renuevan en sus respectivos procesos históricos y se concretan en situaciones y acciones sociales particulares. De ahí la relevancia de la provisión de fondos etnográficos para que los contextos puedan revalidarse con datos empíricos verificables. Observar y preguntarse cómo las instituciones políticas y sanitarias locales orientan su forma de gestionar los riesgos y transmitir la información, contrastar normas y prácticas sociales y médicas en competencia, sin olvidar cómo la ciudadanía se enfrenta a los riesgos, participa y decide. Sin ello, el diálogo que tan de moda está en voz de políticos y expertos, no va a permitir que la comunicación biomédica se equilibre en forma de conversación, active la argumentación y el debate participativo con la ciudadanía.

En la actualidad las polémicas que reclaman la atención ética se sitúan en la pandemia Covid-19 relativa al virus SARS-CoV-2 y las variantes que reciben denominaciones de país, las cepas británica, sudafricana y brasileña, californiana, entre otras. Invocar la salud pública no es motivo para limitar derechos fundamentales, pero, una vez en 2020 la OMS da nombre a la enfermedad la Covid-19 y la califica de pandemia, la comunidad internacional y los gobiernos respectivos se otorgan la autoridad de imponer restricciones a las libertades civiles sobre la movilidad, la reunión y la libertad de expresión. A lo que se añade la vigilancia para asegurar el confinamiento, prevenir la difusión de noticias consideradas bulos y/o también opuestas a la verdad oficial y, correspondientemente, bloquear o sancionar otras voces y cuentas en las redes. Y todo ello al compás de un discurso contradictorio entre seguridad y libertad que genera una suerte de realidad en paralelo. Una parece asegurar que la praxis restrictiva no erosiona derechos y libertades, mientras otra pone en evidencia que las restricciones políticas no tienen base legal, duración ilimitada ni proporcionalidad, por lo que son arbitrarias y discriminatorias (Buxó Rey y González Alcantud, 2020). 
Sin precisar la situación, no hay otra que recurrir a los matices recogidos por las instituciones nacionales e internacionales, los comités europeos tales como, Grupo Europeo sobre Ética de las Ciencias y las Nuevas Tecnologías (EGE), Comité de Bioética del Consejo de Europa (DH-BIO), Comité internacional de Bioética de la Unesco y la Comisión Mundial del Ética del conocimiento científico y la tecnología, Comest, Unesco (IBC). Estas instituciones recogen del marco normativo DDHH los principios del derecho a la salud y la equidad distributiva de los servicios y tratamientos sanitarios, así como el respeto a la privacidad y la autonomía. Pero, además, estos comités los amplifican con recomendaciones tales como, incrementar la solidaridad para conseguir la confianza ciudadana, la responsabilidad individual y colectiva, la vigilancia a las políticas e intervenciones tecnológicas, y, en definitiva, someter las acciones a los principios de transparencia y rendición de cuentas.

El escepticismo público que provocan estas recomendaciones internacionales en contraste con la imposición de restricciones y la falta de transparencia comunicativa de las políticas sanitarias, pone en evidencia la necesidad de un mecanismo corrector. Atender a la multiplicidad de controversias, ideológicas, científicas y morales, sin cuyo reconocimiento y debate no es posible activar y fortalecer el respeto hacia prácticas y decisiones humanas concretas, colectivas e individuales. Prestar atención a los contextos socioculturales para rendir cuenta de la atención profesional a necesidades y practicas locales, la aplicación de terapias biomédicas siempre en interacción con la decisión de las personas que reciben el tratamiento.

Y, en definitiva, darse cuenta que no hay progreso moral si no se activan éticas situadas ya que, la confianza está hecha de relaciones morales múltiples que nacen de un dialogo basado en la información transparente para definir y consensuar los problemas, así como llegar a acuerdos sobre prácticas médicas acordes a la diversidad de las situaciones y la posibilidad de optar entre alternativas.

\section{EXPERTOS Y OFICIANTES}

Hasta hace relativamente poco eran los medios de comunicación los que hacían transitar el conocimiento científico casi en exclusiva, o por lo menos las noticias de sus espectaculares avances. El punto de partida son referencias a las revistas científicas, Lancet, Nature, Science, o a un comunicado institucional, al anunciar una invención o producción de una patente, que se emite en noticias y entrevistas de prensa o en programas de radio y TV, y ahora se multiplican en las redes digitales.

A partir del impacto del proyecto Genoma Humano, entre la complejidad de las repercusiones y el principio de precaución, se crearon masters de comunicación científica que los periodistas cursan para aprender a leer revistas científicas, entrevistar investigadores y entrever los entresijos entre los centros de investigación, las patentes y la producción de los laboratorios farmacéuticos. 
En gran medida, esta era, y aún sigue siendo, la única vía para suscitar el interés de la ciudadanía y esta acceder a este conocimiento privilegiado y sus aplicaciones, y, si acaso, vislumbrar las ventajas o incógnitas relativas al riesgo y la seguridad de estas novedades biomédicas y ambientales, entre otras. Mientras, en la cotidianeidad, la ciudadanía recibe la vulgarización y difusión selectiva de lo científico como marchamo de calidad en la publicidad de combinados vitamínicos, cosméticos y nutricionales, en el amplio escenario de las parafarmacias en los supermercados y en las propias farmacias. De ahí que la apelación a la ciencia haya alcanzado cotas de banalidad al modo como antaño se usaba el nombre de Dios en vano.

En el marco de la pandemia por la Covid-19, el referente ciencia ha sido la justificación de toda gestión y comunicación política y sanitaria. A lo largo del siglo XX hasta hoy, la admiración y la confianza proceden del enlace continuado entre ciencia y progreso cuya asociación se asienta en las virtudes de la objetividad, el rigor, la eficacia, el beneficio, el altruismo, la equidad y la neutralidad, entre muchas otras. Semanticidad de prestigio que ha invisibilizado la cultura científica, esto es, la organización, las políticas científicas, la vinculación con las industrias y los conflictos de interés (Buxó Rey, 2004).

Entre las etnografías de laboratorios (Woolgar, 1991) y las teorías críticas del riesgo, la caja negra de la ciencia y la tecnología se ha abierto poniendo en evidencia que no son simplemente sistemas de conocimiento, sino culturas en acción. De ahí que los proyectos, resultados y patentes queden enmarcados en las implicaciones sociales, éticas y jurídicas por cuanto el sustrato sociocultural conlleva conflictos de interés que requieren la rendición de cuentas. Al decir de Feyerabend (2002), esta cultura organizativa no es neutra ni inseparable de ideologías, prejuicios y motivaciones. Por ello, es importante la transparencia en el diseño, los objetivos y los límites de los procesos de investigación, así como la priorización de enfoques según la asignación de fondos y recursos, sin olvidar las evaluaciones de riesgo relativas a los resultados y la aprobación y comercialización de las patentes. Siendo tan relevante su proyección en el imaginario colectivo por constituir un poder altamente institucionalizado e industrial que, a la vez, requiere un escenario simbólico propio, el parque científico. Un bub de laboratorios, departamentos, oficinas empresariales, además de servicios expertos de comunicación cuyo cometido no es solo divulgar los avances, sino que todo el sistema es garante de la bioseguridad.

Asimismo, la complejidad y la magnitud de la pandemia han obligado a buscar un conector comunicativo que los gobiernos y administraciones locales han asignado a la figura del experto cuyo rol es divulgar la información sanitaria y las recomendaciones a seguir por la sociedad en general. Se escenifica así un espacio comunicativo en el que la presencia del experto, sin mediar ni referenciar los equipos científicos que le puedan asesorar, convierte la información en prescripción y, al modo de un macro ritual, busca concitar la confianza de las audiencias. 
Contemplar un ritual institucional tiene un trasfondo etnográfico que Lisón (2004: 274) ayuda a entender a través de la figura del oficiante. Al ejecutar bajo ciertas condiciones una operación ceremonial, el oficiante no solo se coloca en una posición ritual ventajosa, sino que asciende, posteriormente, a una excelsa plataforma transaccional.

Y no ha sido menos el rol del experto en la pandemia por la Covid-19 en nuestro país. En cada comparecencia, al modo de la plataforma interaccional e intersubjetiva del oficiante ritual, el experto adquiere una suerte de poder impersonal y sus afirmaciones incuestionables pasan a ser la expresión más excelsa de la objetividad en pro del bien común. Así, en ruedas de prensa oficiales y también rutinarias, la tarea del experto es desglosar estadísticas de contagios y muertes, presentar previsiones y generar expectativas relativas a la duración del estado de alerta, el confinamiento, las fases y los cierres perimetrales. Y, ocasionalmente, aportar alguna buena nueva como las curvas planas, las desescaladas y el anuncio de vencer al virus por acceder a la "vacuna", comprar un volumen ingente de unidades y las campañas de distribución por edades y grupos de riesgo. En definitiva, la versión unánime de lo que hay que saber, conviene decidir y los demás seguir. Mientras, poco o nada se dice sobre la gestión, las prácticas de contención del coronavirus, la escasez y la adquisición del material sanitario, la fiabilidad de los diagnósticos, las medicaciones probables, la eficacia relativa de los test, los rastreos y los efectos secundarios de las vacunas.

Bajo la influyente y confortable pantalla del experto oficiante, la gestión y las decisiones políticas quedan bien parapetadas, así como los contextos burocráticos y la adjudicación de presupuestos. Por una parte, se refuerza la impresión que la decisión política queda supeditada o reducida a la decisión técnica en la solución de los problemas y, por otra, contribuye a regular la unanimidad, la concordia y la fidelidad entre instituciones de gobierno, las agencias y los colegios profesionales, resguardándose entre sí y minimizando los conflictos de opinión y el riesgo reputacional.

Esta concordancia institucional se asienta en la ciencia como ideología dominante, y así pasa a operar como autoridad simbiótica en la que no hay rendición de cuentas, ni nadie se sienta obligado a sentirse responsable y menos culpable de sus acciones o decisiones. Una circularidad inescapable donde simultáneamente los consejeros técnicos legitiman el ejercicio del poder mientras los políticos refrendan la responsabilidad de las decisiones en el sistema experto. Así culmina el proceso de acreditación que guía soluciones y sella las decisiones.

Esa circularidad impide la exigencia del principio de transparencia y lo disuelve o encubre al igualar su concepción de la ciencia con la única verdad objetiva, pretensión que ni la propia ciencia subscribe, ya que la validez de las teorías y la actividad investigadora son proyectos abiertos y en evolución. Si la corrección democrática implica la separación de poderes, ejecutivo, legislativo y judicial, asimismo, el estado ha de mantener su separación con las organizaciones espirituales, las iglesias, pero también las organizaciones «inteligentes» relativas a 
las instituciones de investigación y conocimiento. Inmiscuir la fe y las creencias en las decisiones políticas es tan grave como substanciarlas apropiándose del conocimiento científico con fines propios de control y dominación.

Un inconveniente adicional de las ramificaciones políticas del experto es la moda de los transexpertos. Un prototipo de pronosticadores de futuribles que, sin reservas democráticas, se manifiestan como voceros de la ingeniería social con capacidad para construir y monitorizar el mundo en un futuro próximo. Transexpertos que quedan bien representados por las alianzas de una elite financiera conformada por directivos de corporaciones tecnológicas, mandatarios políticos y economistas que promueven la ingeniería social en foros tan mediatizados como el Económico Internacional de Davos. Además de emitir opiniones en nombre de la eco-seguridad del planeta y la felicidad pública, destacados líderes se otorgan el derecho de diseñar futuribles que implican imponer restricciones alimentarias, económicas y de movilidad, aunque con ello arruinen las economías locales, e incluso pronosticar el año en el que se alcanzará la nueva normalidad. Y lo más ocurrente es el fin último cuyo lema es «todos más pobres, pero más felices». Y no menos preocupante, la presentación pública que de la terapia génica PfizerBiotech hace su Ceo, o jefe ejecutivo: "Hoy es un gran día para la ciencia y la bumanidad sin mencionar que es también un éxito empresarial en la comercialización y venta de sus acciones.

En una condición donde el riesgo es glocal y, a la vez, con implicaciones éticas situadas, todo asesoramiento ha de ser transdisciplinar y sus expertos conocidos públicamente. Esto implica que el expertise ha de proceder de equipos profesionales interdisciplinares, capaces de cruzar los datos entre especialidades con el fin de lidiar con problemáticas sociales diferenciadas, transversalizar, redimensionar y vectorizar las evaluaciones y responsabilizarse de sus propuestas y acciones. Nada que ver con una alianza de mandatarios transexpertos que predican su mundo feliz a base de asignarse el monopolio de la verdad y proyectar metas sociales, económicas y ambientales sin aclarar la naturaleza de esa ingeniera social a gran escala, los riesgos de sus propuestas «tecnocientíficas» y los entramados político- financieros-industriales.

Si grave es éticamente que la función del experto sea oportunista al aportar datos, recomendaciones y previsiones incompletas, inconexas e indescifrables, peor es que obstaculice la posibilidad de traducirse en conocimiento útil para la ciudadanía, y que sirva para difuminar u obviar la responsabilidad de quienes toman las decisiones. No transmitir conocimiento fehaciente, no aclarar las iniciativas y los objetivos, ni responsabilizarse de su impacto en la sociedad remite a encubrir de donde emana el poder, criterios y decisiones, en asuntos de bioseguridad. Sin olvidar la precariedad ética de dejar la información en manos de medios de comunicación, prensa y TV, afines y financiados por partidos políticos y redes controladas por corporaciones internacionales.

En definitiva, la irresponsabilidad organizada de crear una cultura de masas en la que la parte menos visible de los mass media es la organizativa cuyo 
producto genérico son industrias de la conciencia (Ortega (1994). Hoy, sin embargo, aparte de la voz unánime del sistema experto al mando y los medios de comunicación afines, hay información complementaria y alternativa que transita en paralelo en medios independientes y en la interactividad de las redes sociales.

La irresponsabilidad organizada de crear una cultura de masas en la que la parte menos visible de los mass media es la organizativa cuyo producto genérico son industrias de la conciencia (Ortega, 1994).

Aparte de la voz unánime del sistema experto al mando y los medios de comunicación afines, la información complementaria y alternativa ha transitado en paralelo en medios independientes y en la interactividad de las redes sociales.

\section{CONTROVERSIAS Y PARTICIPACIÓN PÚBLICA}

¿Es el experto oficiante una artimaña política que interfiere o impide la participación pública?

En su consideración sobre los valores cívicos y los valores conflictivos, Lisón (2010) introduce el factor perplejidad moral para señalar los dilemas de una sociedad que vive en un mundo dominado por el canon científico y el riesgo de las incertezas, lo cual obliga a reflexionar sobre el pensamiento evaluativo de las comunidades que es clave para entender la cooperación, la conformidad, las anomalías y las disrupciones, entre otros.

Sin duda, el pensamiento evaluativo de las comunidades es clave para entender la complejidad de las reacciones y actitudes sociales en situaciones conflictivas. Son su materia prima las actitudes de reconocimiento, aceptación, cumplimiento y, a la vez, desconfianza, negatividad, confrontación, insumisión y disidencia. Sin duda no son fácilmente conjugables, pero sin confrontarlas no es posible configurar una sociedad convivencial.

En el caso de la pandemia, la casta experta y las tácticas de comunicación aportan datos y previsiones que van de la estadística difícil a la opacidad de criterios sin ningún informe técnico de contraste que avale las restricciones y decisiones, excepto la apelación incuestionable a la objetividad de la ciencia. Al oficiar un discurso pontificador, el experto no deja de ser un publicista de las ideas que hay que comprar y, no habiendo una legislación precisa sobre como sancionar el incumplimiento de las restricciones, puesto que las multas todavía son recurribles, entonces se busca que la propaganda política active las virtudes de la consciencia ciudadana. Un entrenamiento previamente utilizado en los repertorios simbólicos y prácticas cívicas relativas al cambio climático que, sin duda, logran incidir en la conducta alimentaria y anticontaminación con el fin de remediar la polución de las aguas, los cultivos y el reciclaje de materiales y embalajes. Virtudes cívicas que, en este caso, se dirigen a la aceptación de vacunarse como un bien para la humanidad. Y, si esa apelación no funciona, se pone en duda o se incumple, los poderes locales, políticos y administraciones, entran en el espinoso territorio de 
amenazar con sancionar a base de imponer un pasaporte de movilidad, gravar con elevadas multas y, si acaso, recluir en zonas aparte.

Lo cierto es que esto concuerda con la idea de los cuerpos dóciles que Foucault (1976) tan bien describe al referirse a la manipulación biopolítica propia de un estado con un aparato supervisor experto para controlar y dominar la libertad de expresión. Aquel que incurra en desvirtuar o no aceptar el discurso oficial, queda marcado por líneas rojas que le condenan al extrarradio, esto es, se le niega tener voz y consideración política para discutir en igualdad de condiciones, sea incluso un profesional especialista en genética, medicina, veterinaria, virología, derecho o psicología. Vista esta negatividad institucional sorprende que, excepto a los afines del régimen, se catalogue a aquellos que no coinciden y se posicionan críticamente como negacionistas y, con frecuencia, se les asigne el territorio ultramontano de la disidencia.

Y, aun así, en la esfera pública se dan tendencias de mayor y menor participación que por mor de la brevedad cabe situar entre dos perfiles, con variantes, que oscilan entre el confort de la actitud pasiva y la responsabilidad de la participación activa. En el extremo de la pasividad, cabe situar la confianza por afinidad ideológica, pero también la aceptabilidad ignorante por no estar ilustrado en el conocimiento, los convenios y obligaciones biomédicas, además de una cierta amnesia por desconexión entre los mensajes institucionales y los entresijos políticos que guían las restricciones. Esto induce a situarse en la posición inactiva del paciente sumiso y agradecido en espera de las dádivas eficaces del sistema sanitario y la nueva normalidad prometida. A pesar de que esta confianza pueda ir en su contra, el confort de las creencias, la ideología clientelar y la banalidad moral pueden conjuntarse para que esta actitud ciudadana sea cómplice de la mala praxis y la perdida irresponsable de sus derechos.

Mientras que la actitud participativa se activa con la idea que es un derecho y una obligación entender y si acaso contravenir las imposiciones poniendo en duda los criterios que guían la gestión y las políticas de control que se hacen en nombre del bien público. Subvertir la obediencia ignorante por la responsabilidad cívica implica buscar fuentes de información alternativas, contrastar críticamente los datos y moverse, según las posibilidades, entre la denuncia, la insumisión civil y el activismo. La exigencia es la libertad positiva (Berlin, 2014) mientras que la desobediencia civil tiene una larga trayectoria inspirada en la conciencia ambiental de finales del XIX (Thoreau, 2018). Y hoy razonado con precisión por Gutiérrez Alonso (2021): "nuestro deber no puede ser otro que desconfiar en las instituciones para conservarlas, identificar y denunciar sus frecuentes mentiras, artimañas, excesos, y desviaciones; fiscalizar y someter a control y denuncia todo su ser, entramado, organización, motivaciones, recursos humanos, actos y decisiones. Esto es lo que nos hace ser buenos ciudadanos» y no al revés.

La intromisión en la esfera privada de los medios de comunicación entrena a la ciudadanía para que la información de este poder mediático piense por ella, incremente la credibilidad y la conformidad con la realidad de las noticias. Siendo 
difícil la identificación y la definición de los riesgos biomédicos y de bioseguridad, la comunicación inconclusa e interesada pone nuevos retos que, de no encararse, conducen seriamente a la incertidumbre, los miedos y las fantasías conspirativas.

Cierto es que las instituciones científicas y bioéticas abogan por buscar fórmulas para convencer e incentivar en lugar de obligar y multar. Sin embargo, esto no resuelve el riesgo moral de redistribuir soluciones injustas y faltar al consenso requerido por todas las directrices y convenios de la Comunidad Europea que conminan a tener en cuenta no solo la autonomía personal para decidir y consentir, sino también asegurar la participación ciudadana informada sin sometimiento a la propaganda.

Si no se atienden esas advertencias, la ciudadanía no tiene otra opción para bregar contra la ambigüedad y la imposición que caminar entre versiones y controversias. Estas se nutren de la información y los debates que transitan en las redes sociales avivadas por grupos de opinión, a veces versos sueltos en conexión con los afines de otros blogs, sean periodistas, especialistas en virología, medicina, veterinarios, y, ocasionalmente instituciones científicas y rara vez colegios profesionales. En cualquier caso, la información en red y la interactividad de las redes sociales aportan información plural, debates profesionales de contraste y posicionamientos diversos con referentes nacionales e internacionales. Esto genera controversias de gran riqueza informativa a partir de la cual se adquieren criterios para opinar, disentir y también aceptar, criticar u oponerse a las restricciones políticas y las medidas sanitarias.

No hace tanto, los riesgos en bioseguridad se atendían con reglamentaciones orientadas por el principio de precaución. Moratorias que podían afectar las líneas de investigación, la aprobación de patentes y, consecuentemente la producción industrial y la comercialización. Ahora, entre presión y oportunidad, con medias o sin evidencias experimentales completas, entre emergencia y celeridad, la aprobación de fármacos en las agencias regulatorias no sigue una tramitación dilatoria, sino que transita como una terapia ilusionante remozada de gran innovación. Sin compromiso con la transparencia y la rendición de cuentas, sean laboratorios, agencias reguladoras y gobernanzas sanitarias, la sensación resultante es de arbitrariedad, como si se tratase de compromisos entre fines incompatibles que no permiten asegurar los resultados, excepto por estadísticas aproximativas, ni tampoco rendir cuentas ante los posibles efectos adversos.

En conjunto, las controversias se sitúan en aquellos puntos donde las expectativas de superar la situación son más altas, pero también el resultado de las medidas y restricciones son menos acertadas. Las dudas y las incertidumbres atingentes a la salud y la privacidad movilizan la participación que es muy activa en las redes por constituir un reto a su comprensión y capacidad en dilucidar criterios, versiones y posiciones en el panorama político y sanitario. Las controversias aportan una provisión de fondos a base de datos contrastables y en competencia en los que concurren opiniones y referencias relativas a prácticas sanitarias 
generales y situadas, normativas y convenios, junto con la ineludible intriga y las medias verdades.

Concurren en la red y en diversos medios de comunicación, públicos y privados, el comentario y la discusión sobre los edictos, las contradicciones y las propias correcciones de la OMS, la promulgación de marcos normativos y resoluciones del Consejo de Europa, Centros nacionales de biotecnología, Asociaciones de medicina, vacunología, veterinaria, Agencias reguladoras del medicamento, Fundaciones, Asociaciones independientes, locales, nacionales e internacionales, Médicos y Biólogos por la verdad, Policías por la libertad y Manifestaciones en grupos de oposición y reivindicación. Y un sinfín de Twitters y Blogs que aportan información y multiplican los debates en la red y que también transitan en radios y televisiones independientes apoyadas por donativos y subscripciones a través de códigos QR.

Se duda, opina y discute sobre las restricciones relativas al confinamiento, los cierres perimetrales, el uso generalizado y/o relativo a situaciones de las mascarillas, la distancia entre personas y/o convivientes en espacios abiertos y cerrados, los cortes perimetrales de países, autonomías, ciudades y pueblos, la atención y el encarnizamiento terapéutico, los medicamentos y la ausencia de autopsias. La reacción lenta de las instancias políticas que han vehiculado las restricciones con medidas tradicionales tales como, confinar, distanciar, enmascarar y practicas higiénicas habituales, sin explicar los criterios o razones que guían los protocolos de actuación ni aportar otras fórmulas contextualizadas que eviten la arbitrariedad de las medidas.

Si al principio fueron los medicamentos el motivo de interés en las redes, sus diferencias y posibilidades, los laboratorios que los producían (Sanofi, Merck, etc.) y la espera atenta por la aprobación de las agencias reguladoras del medicamente, especialmente FDA (USA) y EMA (CE). A falta de información, pronto se recurrió a los planes $\mathrm{B}$, recursos de sanación a base de cotejar prácticas entre productos básicos y tradicionales, desde la hidrocloroquina, la artemisa, entre otros; y, puesto que la sensación generalizada era del sálvese quien pueda, se optó por el recurso de reforzar el sistema inmune, y ahí desfilaron todas las vitaminas C, D y los minerales Zinc, entre otros, así como una alimentación y ejercicios adecuados. Y de este plan B pronto se hicieron eco las farmacéuticas que publicitaron nuevos productos para reforzar el sistema inmunitario. A esto siguieron los dispositivos para diagnosticar y medir las prevalencias, el famoso PCR y las consiguientes dudas de lo que mide realmente, los falsos positivos y la eficacia probable en asegurar el control de contagios en reuniones y desplazamiento entre países, comunidades, ayuntamientos y familias.

Es, sin embargo, el coronavirus el que acumuló primero el protagonismo y atención pormenorizada: el origen, su carácter natural o artificial, la distinción entre nombre virus SARS-CoV-2 y la enfermedad Covid-19, los virus mutantes, las cepas, los vectores virales y todo el campo semántico relativo contagiar, infectar, enfermar, inmunidad de grupo, morirse de y por, las inmunidades de grupo y 
asintomáticos con y sin vacuna y el potencial de contagio a corto, medio y largo plazo. Y las razones de la concentración y la expansión del virus, incluso la incidencia de la radiación electromagnética.

Hasta llegar al antídoto estrella, la solución de todos los males que ha sido anunciado y difundido con el nombre tradicional de "vacuna». Todavía hoy se debate sobre la composición, las diferencias entre el fármaco génico, moléculas de ácido ribonucleico mensajero (ARNm) cuya inoculación aporta una proteína spike o llave maestra para introducir instrucciones genéticas en células receptoras para así crear la reacción inmunitaria. Y, y posteriormente, otros fármacos tipo vector viral con fragmentos de virus atenuados o inactivados. Las características y eficacias de las primeras según los laboratorios de renombre Pfizer-Biotech, Moderna, y también los otros fármacos de AstraZeneca, Sputnik, entre otros; la protección y daños, el riesgo de efectos adversos absoluto y relativo, entre otros mil detalles. Y así siguen las redes en busca de otros medicamente neutralizantes y eficacias más amplias.

Más allá del producto y la enfermedad siguen las controversias sobre las implicaciones sociales, éticas y jurídicas. Los protocolos de actuación, la distribución equitativa por grupos de riesgo y edades, ejemplos de mala praxis o desconsideración en el procedimiento de vacunar a los mayores, el oportunismo de acceder primero por el cargo y los tratamientos masivos sin opciones para elegir marcas y también los retrasos en la distribución y la aplicación.

Ahora bien, donde se concentran las controversias es sobre la bioseguridad, las incertezas por ser un fármaco de experimentación fase 3 autorizado por ser un fármaco AES, autorizado por emergencia sanitaria. Los riesgos añadidos y eventuales en la genética personal por toxicidad, la supresión de respuestas inmunológicas y otros efectos adversos, incluso la protección relativa según surjan nuevas cepas. La carencia de información estandarizada sobre la representatividad de los participantes y edades, el ciclo vital de las terapias génicas, los protocolos de experimentación, muestras y ensayos clínicos, fases de estudio, porcentajes de la eficacia, latencia y duración de la inmunidad. Y ya en el proceso de aplicación, las dosis, la conservación, los formularios aclarativos del compuesto, las garantías, la rendición de cuentas, sin olvidar la parte económica de los contratos entre las industrias y los gobiernos soberanos, los incumplimientos comerciales, la financiación y la actividad en Bolsa de las industrias farmacéuticas.

Etnográficamente, es interesante observar la interpenetración simbólica entre fármaco e identidad nacional, lo cual se manifiesta en las preferencias o reservas de la ciudadanía de diferentes países por la inoculación de una u otro tratamiento génico. No en vano, a los fármacos se les reconoce simultáneamente con el nombre del laboratorio y/o el país, la ciudad del lab o, simplemente, un rasgo asociado a un éxito tecnológico, sea un cohete o un baby champú, por ejemplo, la vacuna rusa denominada «Sputnik V» o la vacuna estadounidense "Janssen» de Johnson\&Johnson. 
Y, finalmente, la contraposición de seguridad y libertad, la vigilancia versus la privacidad relativa a implantar registros, rastreadores, pasaportes, dispositivos en los móviles como instrumentos de detección y la insinuación de campos donde concentrar a los resistentes a vacunarse. Todo ello aporta retos añadidos a la complejidad, percepción y comprensión del riesgo público intervenido y decidido por las políticas sanitarias y las agencias reguladoras. Si bien antes tardaban en reaccionar y/o recurrir a soluciones dilatorias en nombre del principio de precaución, moratorias o, simplemente quedar en manos de la lentitud del proceso de reglamentación, ahora imponen la celeridad urgente por emergencia sanitaria. Y, en el extremo más crítico, se abren opiniones sobre el fin último de la pandemia que no es otro que la ingeniería social de los poderes de las corporaciones financieras y high tech. Una pandemia que se extiende a la vacunación que no es otra cosa que un diseño para programar los seres humanos.

Es preciso constatar que hay posiciones críticas que no quieren someterse a las terapias génicas, actitud que denominan Auschwitz y que encuentran apoyo en el marco normativo del Consejo de Europa. En concreto la resolución 2361, en la que se requiere que los ciudadanos estén informados y no se les obligue ni presione si no lo desean y que tampoco sean discriminados.

La pandemia ha puesto de relieve la debilidad de las instituciones democráticas cuando de resolver problemas se trata y de inspirar confianza y seguridad en la ciudadanía. Siendo grande el escepticismo por la pésima, contradictoria, quizás interesada, comunicación de las instancias gubernamentales, todavía genera más desconfianza que la protección que ofrece el Estado sea a base de exigir fe en el rigor de la ciencia y cumplir virtuosamente los preceptos políticos, y más si la protección progresa en la dirección de imponer sanciones sea en forma de multas o pasaportes de buena conducta.

Y todavía es más preocupante si se impone una dominación silenciosa y primitiva, un ostracismo incapaz de abrirse a las inquietudes de la ciudadanía y aceptar en buena lid la controversia. Sin olvidar la incapacidad de colaborar con la ciudadanía en nombre del dialogo que tanto predican las instituciones de la CE.

Aparte de la provisión de datos y criterios que aportan las controversias, la ciudadanía dispone, además, de la proximidad de la experiencia observable que le permite revalidar datos y opiniones selectivamente con bases empíricas identificables en sus grupos de edad, formación e ideología, en los contextos de situación de sus comunidades, ciudades y pueblos. El conocimiento en acción y la precaución reflexiva de la experiencia cultural es información pertinente para ampliar las miras de las autoridades políticas y sanitarias; de ahí que su implicación sea parte ineludible para debatir las matrices del riesgo en la que todos están implicados, así como consensuar soluciones y garantizar la proporcionalidad de los compromisos, incluso simetrizar los sacrificios inevitables.

Sin duda, la alfabetización científica y ética permite ser un ciudadano más activo y efectivo para ejercer derechos y obligaciones cívicas. Participar y colaborar en un debate requiere estar al caso de los criterios que permiten argumentar 
y tomar decisiones sobre riesgos y beneficios, las razones o los intereses que sustentan las prioridades y los procedimientos, y sobre todo aprender las condiciones iguales o asimétricas a las que queda sujeta la acción de las partes para llegar a consensos y tomar decisiones. Y si el conocimiento científico escapa en sus detalles, los conflictos de interés de las políticas científicas, las instituciones sanitarias y las industrias farmacéuticas, son más fácilmente observables, discutibles y, quizás, controlables.

Hace años que el modelo déficit 0 , así denominado por el grupo de investigación en bioética de Lancaster University en referencia al desconocimiento de la ciudadanía para informarse, debatir y decidir, puso en evidencia que, si la gente desconfía de la ciencia, o de la biomedicina, o de las recomendaciones políticas, no es porque sea ignorante, si la gente desconfía, es porque tiene buenas razones para ello.

Ciertamente, la Comunidad Europea se ha volcado en promocionar en sus programas marco, VII y VII, estudios y redes de expertos dedicadas no sólo a identificar problemas probables como resultado de los avances tecnocientíficos, sino a desarrollar proyectos que faciliten adquirir estos conocimientos a la ciudadanía. En este sentido, son diversas las metodologías y las actividades que se promueven para desplegar el dialogo ciencia-sociedad: abrir las puertas de los laboratorios, realizar conferencias y exposiciones en facultades y en museos de la ciencia y, a través de las mismas y/o propuestas aparte, dinamizar grupos de diferentes edades en escuelas y talleres científicos, los Trams: training and mentoring of science shops y también la formación de jurados. En cualquiera de estas actividades se crean condiciones pedagógicas no solo sobre aspectos tecnocientíficos y biojuridicos, sino también ejercitarse con prácticas y contextos que permiten adquirir criterios, definir los problemas y valorar los dilemas éticos con ejemplificaciones relativas a cuestiones sobre la equidad, el consentimiento en la atención sanitaria, las terapias y los medicamentos, entre otros.

En documentos diversos procedentes de centros de investigación, organizaciones y agencias de la Comunidad Europea, en su gran mayoría propiciados por Ethical, Legal and Social Issues. Para el Horizonte 2020, se recomienda un tratamiento prospectivo para animar el diálogo usando la simulación y la ficción como recursos metodológicos que permitan explorar y evaluar escenarios de futuro. Sin duda, esto nada tiene que ver con mezclar ficción y datos científicos y sociales. Introducir variables utópicas y distópicas contribuye a distorsionar los datos y generar inconsistencias en los argumentos y, finalmente, inutilizar los indicadores. Si acaso, tiene que ayudar a desvelar el aura de ficción que, al producir espléndidos escenarios de futuro, fascina en todas las edades, refuerza los argumentos publicitarios en toda suerte de productos y, ya no digamos, en los proyectos de magnates y corporaciones, como la agenda 2030, difundidos en los medios de comunicación afines.

En el contexto de la pandemia, cabe observar retrospectivamente que la improvisación, las medidas y restricciones variables y en contradicción fueron los 
ingredientes de las declaraciones, OMS y las recomendaciones de gobiernos e instituciones en general. Cabe preguntarse, por qué no se han realizado proyectos prospectivos para entrenar no solo a políticos, expertos y sanitarios, sino también a la ciudadanía.

Sorprende por el hecho que hay una simulación previa realizada con recursos internacionales por la Fundación Gavi, esto es, la Alianza para la vacunación, una asociación internacional de la que forman parte la misma OMS, el Banco Mundial y en la que concurren diversas empresas farmacéuticas y fundaciones filantrópicas y corporaciones high tech. Cierto que el objetivo original de la Fundación es mejorar el acceso a las vacunas en los países en desarrollo, pero, concretamente, en el 2019 desarrollan el Evento 201, la simulación de la propagación de una infección vírica real. Un material de referencia clave, aplicable glocalmente, para entrenar a la ciudadanía y a los gobiernos respectivos en la coordinación de criterios, consensos y decisiones respecto a la salud pública, las economías, la movilidad y las censuras tecnológicas en las redes de la sociedad en general. Y no será porque no haya en todos los países institutos de prospectiva que disponen de esa información y las metodologías para prepararse ante desafíos probables como, por ejemplo, el cambio climático. Sin duda, esto hubiese permitido activar aprendizajes y debates con el fin de detectar y analizar problemas, tensiones y anomalías trasladables a previsiones y medidas alternativas en función de soluciones prácticas contextualizadas.

Y sorprende todavía más porque esta es la apuesta por el diálogo permanente que los programas de la $\mathrm{CE}$ recomiendan entre las instituciones y la sociedad en su conjunto. Teniendo en cuenta, por una parte, que la demanda de dialogo es por el interés de las instituciones de investigación y las industrias farmacéuticas, en referencia al riesgo de la desconfianza pública. Esto es, inhibir la confianza de contribuyentes y consumidores en los proyectos de investigación, patentes y comercialización supone disminuir la aceptabilidad pública, lo cual tiene consecuencias en la inversión privada, la financiación pública y el consumo. Y, por otra, no cabe desdeñar que, en el marco de las sociedades democráticas, la confianza pública se ha depositado tradicionalmente en la representatividad de las instituciones y los textos fundantes de las Constituciones, Declaraciones, Convenios y Pactos internacionales.

Si estos marcos de amparo se fragilizan por razones ideológicas o se inutilizan por el choque de intereses entre las causas a proteger, se produce una distorsión de valores morales al usar los derechos humanos para imponer un bien común basado en un modelo de beneficencia partidista. Un secuestro que no sólo anula el potencial ciudadano para lidiar con situaciones adversas, sino que incrementa la disidencia.

Las éticas situadas matizan el uso de los principios y son prudentes con el consenso superficial si interfiere en la proporcionalidad entre seguridad y libertad. Son las reglas del consenso las que tienen que nutrir las recomendaciones políticas si se quiere que sus metas sean legítimas, en especial cuando las decisiones 
que se cuestionan o discuten hacen referencia a la utilización del cuerpo, la privacidad y la autonomía personal. Sin estos requisitos, incluso el formulario exigible del consentimiento informado puede llegar a ser un instrumento impositivo o intimidante que entra en colisión con el derecho a la decisión informada y vulnera la autonomía de las personas.

En cualquier interacción interesada es clave el consentimiento informado lo cual ya es una práctica común, pero no siempre con garantías informativas suficientes. En antropoética (Fluehr-Loban, 1991) se considera un requisito para realizar trabajo de campo y se solicita a modo de permiso para preguntar, observar, guardar y publicar la información etnográfica. Y también en el sistema sanitario ya es obligatorio como documento firmado por contener la información de las características de la praxis médica y la aceptación del paciente. Sin embargo, en las restricciones por emergencia sanitaria, el consentimiento informado ha sido éticamente carencial, insuficiente para informar al paciente sobre las características del tratamiento génico y por las condiciones de la praxis médica. Así, es lamentable la imagen de la inoculación a gente de edad avanzada a través de la ventanilla del coche formando una larga cola.

\section{CODA}

De ahí la relevancia de la ética situada que no se define por lo normativo, sino por la acción que contribuye a realizar, en este caso, ir más allá de la lectura de un texto y firma, para implicar la participación ciudadana en el debate público informado y así contribuir a definir y consensuar los problemas y la praxis médica de forma más acorde a la diversidad de las situaciones y la posibilidad de optar entre alternativas.

En este caso, si bien no es tarea fácil dar contenido y viabilidad al dialogo, no hay otro camino para identificar los problemas y definir los riesgos que afectan a todos por igual. Entrenarse y ejercitar la reflexividad para razonar y evaluar las expectativas, incertidumbres y suspicacias que proyectan riesgos y metas (investigación, patentes, equidad distributiva y aplicaciones), es la única vía que capacita para participar en encuestas, debates y deliberaciones, y, progresivamente, colaborar en el debate informado que conduce a la toma de decisiones.

En definitiva, una sociedad democrática en plenitud, no solo es representativa sino también deliberativa. Votar sin discutir no es democrático (Elster, 2001) por lo cual la corresponsabilidad ciudadana de participar y discutir es parte ineludible del proceso de tomar decisiones con fines públicos. El derecho al debate informado no es una simple transferencia de información, está asociado a un tipo de gobernanza interactiva que, asentada en la imparcialidad, facilita el debate en la definición de los problemas, las necesidades, las restricciones y los servicios; esto es, las ventajas y desventajas, opciones y alternativas sin lo cual no es posible deliberar y llegar a consensuar acuerdos. 
En condiciones de pandemia, el dialogo recomendado por la CE entre política, ciencia y sociedad, implica refinar la representatividad en la dirección de la deliberación pública. Si la obligación ciudadana es participar, aportar ideas, argumentos y experiencias situadas para el debate, por su parte las administraciones respectivas del Estado han de encontrar los cauces donde establecer la colaboración, aportar información y presentar las razones y las motivaciones que sustentan las prioridades y las precauciones, medidas y restricciones, sean confinamientos $\mathrm{O}$ tratamientos médicos posibles, alternativos y complementarios. Y con los acuerdos consensuados, el gobierno, como servidor público, ha de cumplir el mandato de gestionar las decisiones por encima de preferencias ideológicas.

Sin estos aprendizajes colaborativos no es posible implicar en la deliberación al conjunto de la sociedad, ciudadanos, instituciones de investigación, poderes públicos, industria y medios de comunicación. Ni tampoco asegurar el compromiso ético en el que han de concurrir necesariamente la responsabilidad, la integridad, la imparcialidad y la transparencia como base de la asunción de riesgos de toda la sociedad.

Ya en los años 70 Barbara Culliton (1985: 146) decía:

Public participation is not dangerous for the scientific enterprise. It's time consuming and it is likely to lead to restraints that previously were not imposed. Nevertheless the restraints that come from ethical considerations cannot be dismissed as inappropriate. In any case, they are part of the social cost of democracy.

\section{REFERENCIAS BIBLIOGRÁFICAS}

AAA, American Anthropological Association. (1999). Statement Declaration on Anthropology and Human Rights. https://www.americananthro.org/ConnectWithAAA/Content. aspx?ItemNumber $=1880$.

Berlin, I. (2014). Dos conceptos de libertad. El fin justifica los medios. Madrid: Alianza Editorial.

Blackburn, S. (1998). Ruling Passions. Oxford: Clarendon Press.

Buxó Rey, M. J. y González Alcantud, J. A. (coords.). (2020). Pandemia y Confinamiento, malestar en la cultura global. Granada: Editorial Universidad Granada.

Buxó Rey, M. J. (2010). Nanodiálogo: La comunicación y la implicación pública en los avances nanobiotecnológicos. En M. Casado (ed.), Bioética y Nanotecnología (pp. 63-76). Pamplona: Thomson Reuters y Civitas.

Buxó Rey, M. J. (2004). Science in a cultural key. Contributions to Science, 2(4), pp. 525-528.

Culliton, B. (1985). The public and the media. En R. Clarke (ed.), Science and Technology in World Development (pp. 146-154). Oxford: Oxford University Press.

Elster, J. (comp.). (2001). La democracia deliberativa. Barcelona: Gedisa.

Feyerabend, P. (2002). Contra el método. Barcelona: Ediciones Folio.

Fluehr-Lobban, C. (1994). Informed Consent in Anthropological Research: We are not Exempt. Human Organization, 53(1), pp. 1-10.

Foucault, M. (1976). Vigilar y castigar. México: Siglo XXI. 
Gutiérrez Alonso, J. J. (2021). Desconfianza legítima. https://disidentia.com/desconfianza -legitima/.

Herskovits, M. (1973). Cultural Relativism. New York: Vintage Books.

Ignatieff, M. (2001). Human Rights as Politics and Idolatry. Princeton: Princeton University Press.

Illich, I. (1973). Tools for conviviality. New York: Harper \& Row.

Lisón Tolosana, C. (2010). ¿Qué es ser hombre?. Valores cívicos y Conflictos en la Galicia profunda. Madrid: Ediciones Akal.

Lisón Tolosana, C. (2008). Ética y Antropología. En A. B. Espina Barrio (coord.),Antropología aplicada en Iberoamérica (pp. 16-22). Recife: Fundación Nabuco.

Lisón Tolosana, C. (2004). La España mental 2, el problema del mal. Madrid: Ediciones Akal.

Macklin, R. (2003). Dignity is a useless concept. BMJ medical publications, 327, pp. 1419-1420.

Ortega, F. (1994). El mito de la modernización. Barcelona: Editorial Anthropos.

Pinker, S. (2008, 28 de mayo). The stupidity of dignity. The New Republic.

Rawls, J. (2006). Teoría de la Justicia. México, D. F.: Fondo de Cultura Económica.

Rorty, R. (1997). ¿Esperanza o conocimiento? Una introducción al pragmatismo. México: Fondo de Cultura Económica.

Sandel, M. (1982). Liberalism and the Limits of Justice. Cambridge: Cambridge University Press.

Thoreau, H. D. (2018). Desobediencia Civil. Buenos Aires: Interzona Editora.

Unesco. (1995). Nuestra Diversidad Creativa, Informe de la Comisión Mundial de Cultura y Desarrollo.

Unesco (2005). Declaración Universal sobre Bioética y Derechos Humanos. http://portal. unesco.org/es/ev.phpURL_ID=31058\&URL_DO=DO_TOPIC\&URL_SECTION=201.html

Woolgar, S. (1991). Ciencia: abriendo la caja negra. Barcelona: Editorial Anthropos. 